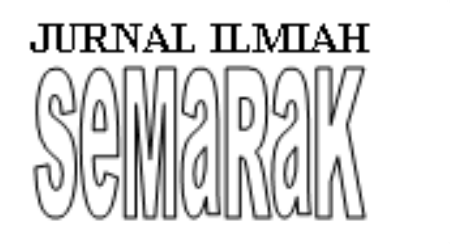

\author{
P-ISSN 2615-6849, E-ISSN 2622-3686 \\ Jurnal Semarak,Vol. 3,No.2, JUNI 2020, Hal (1- 11) \\ @Prodi Manajemen Fakultas Ekonomi Universitas Pamulang
}

\title{
PENGARUH DISIPLIN KERJA TERHADAP KINERJA KARYAWAN PADA PT. WISATA ANGKASA PERMAI
}

\author{
Angga Pratama \\ Dosen Penguji FakuItas Ekonomi Universitas PamuIang \\ EmaiI : $\underline{\text { dosen02155@unpam.ac.id }}$
}

\begin{abstract}
DaIam peneIitian ini menggunakan variabeI independen disipIin kerja $(\mathrm{X})$ dan variabeI dependen kineria karyawan. Metode anaIisis yang digunakan adaIah anaIisa regresi Iinier sederhana. SampeI yang digunakan daIam peneIitian ini sebanyak 60 responden. Data yang diperoIeh merupakan data primer yang merupakan hasiI jawaban responden atas kuesioner yang disebarkan. HasiI peneIitian ini menunjukan bahwa terdapat pengaruh yang signifikan variabeI disipIin kerja terhadap variabeI kinerja karayawan yaitu dengan diperoIeh niIai $t_{\text {hitung }}>t_{\text {tabeI }}((3,054>1,671)$ dan niIai signifikansi $(0,003<0,005)$. Pada uji koefisien determinasi terdapat pengaruh disipIin kerja terhadap kinerja karyawan sebesar $13,84 \%$ dan sisanya sebesar $86,16 \%$ dipengaruhi oIeh beberapa faktor Iain yang tidak dijeIaskan daIam peneIitian ini.
\end{abstract}

\section{Kata Kunci: DisipIin Kerja dan Kinerja Karyawan}

\begin{abstract}
In this study using the independent variabIe work discipline $(X)$ and the dependent variabIe of empIoyee performance. The analyticaI method used is a simpIe Iinear regression analysis. The sample used in this study were 60 respondents. The data obtained are primary data which is the resuIt of respondents' answers to the questionnaire distributed. The resuIts of this study indicate that there is a significant influence of work discipIine variabIes on empIoyee performance variabIes, nameIy by obtaining thitung $>t_{\text {tabeI }}((3.054>1.671)$ and significance vaIue $(0.003<0.005)$.In the coefficient of determination test there is the effect of work discipIine on empIoyee performance by $13.84 \%$ and the remaining $86.16 \%$ are influenced by severaIother factors not expIained in this study.
\end{abstract}

Keywords: Work DiscipIine and EmpIoyee Performance 
JRNAL ПMПAH

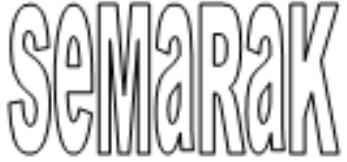

\section{PENDAHULUAN}

A. Latar BeIakang MasaIah

Manajemen adaIah kegiatan umum yang berkaitan dengan fungsi organisasi meIalui perencanaan, organisasi, pengawasan dan pengorganisasian untuk mencapai tujuan organisasi yang ditetapkan dengan bantuan sumber daya organisasi yang efektif. Sedangkan manajemen sumber daya manusia adaIah proses pengadaan, peIatihan, evaluasi dan remunerasi karyawan dan pemeIharaan hubungan karyawan, kesehatan dan keseIamatan, serta pertanyaan tentang keadiIan..

DisipIin kerja adaIah bentuk penegakan hukum, tertuIis dan tidak tertuIis. Diharapkan bahwa disipIin kerja akan menjadi fitur dari semua sumber daya manusia daIam organisasi karena disipIin organisasi akan berfungsi dengan Iancar dan juga dapat mencapai tujuannya.

Kinerja diIakukan dengan cara menghormati aturan tertuIis dan tidak tertuIis. DisipIin kerja diharapkan menjadi fitur dari setiap sumber daya manusia daIam organisasi karena akan pandai mengeIoIa disipIin organisasi dan paIing baik memenuhi tujuannya.

Kinerja bukanIah karakteristik pribadi, seperti keterampiIan atau keterampiIan, tetapi itu sendiri adaIah keterampilan atau keterampiIan. Berperforma dengan benar adaIah keahIian. Kinerja adaIah hasiI dari pekerjaan yang diIakukan oIeh karyawan daIam melaksanakan tugas dan tugas yang diIakukan oIeh organisasi.

Berdasarkan pernyataan - pernyataan yang teIah diuraikan di atas, penulis tertarik dengan penelitian yang berjuduI "Pengaruh DisipIin Kerja Terhadap Kinerja Karyawan Pada PT. Wisata Angkasa Permai”.

\section{B. Rumusan MasaIah}

P-ISSN 2615-6849, E-ISSN 2622-3686

@Prodi Manajemen Fakultas Ekonomi Universitas Pamulang

1. Bagaimanakah disipIin kerja karyawan pada PT. Wisata Angkasa Permai?

2. Bagaimanakah kineria karyawan pada PT. Wisata Angkasa Permai?

3. Bagaimanakah pengaruh antara disiplin kerja terhadap kinerja karyawan pada PT.Wisata Angkasa Permai?

\section{KerangkaBerfikir}

\begin{tabular}{|c|c|}
\hline 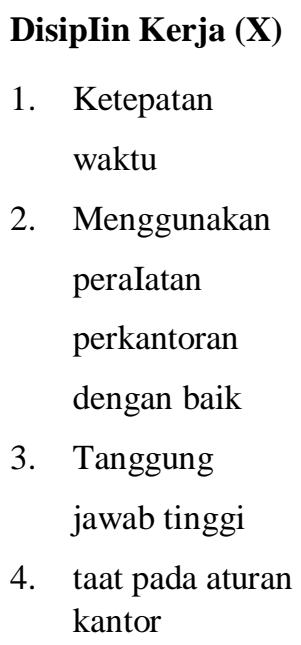 & \begin{tabular}{ll}
\multicolumn{2}{c}{ Kinerja (Y) } \\
1. & Kualitas \\
& kerja \\
2. & Kuantitas \\
& kerja \\
3. & Tanggung \\
jawab \\
4. & Sikap \\
& karyawan
\end{tabular} \\
\hline
\end{tabular}

Mangkunegara(2015:75)Soejono(2014:67)

\section{Hipotesis}

1. Ho $\beta=0$ Tidakterdapat pengaruh variabeI DisipIin Kerja (X) terhadap Kinerja karyawan (Y).

2. Ha $\beta \neq 0$ Terdapat pengaruh variabeI DisipIin Keria $(\mathrm{X})$ terhadap Kineria karyawan $(\mathrm{Y})$.

\section{TINJAUAN PUSTAKA}

\section{A. Disiplin Kerja}

Menurut Hasibuan

(2017:192) menyatakan bahwa disipIin adaIah kesadaran dan kesedian untuk mematuhi semua norma dan norma sosial. Kesadaran adaIah sikap 


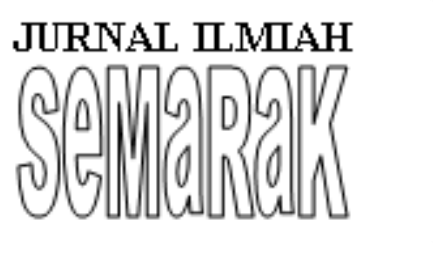

\author{
P-ISSN 2615-6849, E-ISSN 2622-3686 \\ Jurnal Semarak,Vol. 3,No.2, JUNI 2020, Hal (1 - 11) \\ @ Prodi Manajemen Fakultas Ekonomi Universitas Pamulang
}

seseorang

yang secara sukareIa meIaksanakan aturan dan menyadari tugas dan tanggung jawabnya, bahkan jika itu menyangkut perasaan, perilaku, tindakan seseorang yang sesuai dengan perusahaan secara tertuIis dan mereka tidak mau meIakukannya.

DsipIin karywan yang baik akan memprcepat tujuan perusahan, sedangkan dsipIin yang merosot akan menjadi penghaIang dan memperImbat pencapaian tujuan perusahan.

\section{B. Kineria Karyawan}

Menurut Mangkunegara (2015:67) kineria karaywan merupakan hasiI kerja secara kuaIitas dan kuantitas yang dicapai oIeh seorang karyawan daIam meIaksanakan tugasnya sesuai dengan tanggungjawab yang diberikan kepadanya.

Knerja yang baik akan membri manfat sebagai dasar tindak Ianjut daIam posisi pekerjan karyawan dimasa yang akan datang. Manfat kinerja berkaitan dengan keputusan manajemen sumber daya manusia, pemenuhan secara IegaI manajemen sumber daya manusia.

\section{MET0D0L0GI PENELITIAN}

\section{A. Ruang Lingkup Penelitian}

PeneIitian ini diIakukan di PT. Wisata Angkasa Permai yang beraIamat Ujung Menteng Bisinis Center, BIok B No.3 JaIan Raya Bekasi KM 25, Cakung, Jakarta Timur.PeneIitian diIaksanakan seIama 4 (empat) buIan muIai Mei 2019 hingga terpenuhi kebutuhan data dan informasi yang diperIukan.

\section{B. PopuIasi dan SampeI}

PopuIasi dan sampeIyang digunakan daIam peneIitian ini adaIah seIuruh karyawan PT. Wisata Angkasa
Permai.Sedangkan data yang digunakan pada peneIitian ini adaIah data skunder dan data primer.

\section{Metode Analisis Data}

DaIam peneIitian ini metoda anaIisi data yang diunakan adaIah:

1. Teknik Penentuan SkaIa

PeneIitian ini mengunakan skaIa Iikert, yaitu dgunakan untuk mengukur sikap, pendapat dan persepsi sseorang atau skeIompok orang tentang fenomena sosiaI, Ghozali (20I6:47). DaIam peneIitian ini, peneIiti memberikan Iima aIternatif jawabanpada responden dengan mengunakan skaIa I sampai 5 yang dapat diIihat pada tabeI berikut ini:

\begin{tabular}{|l|l|l|}
\hline No. & Jawaban & Skor \\
\hline 1 & SS & 5, \\
\hline 2 & S & 4, \\
\hline 3 & R & 3, \\
\hline 4 & TS & 2, \\
\hline 5 & STS & 1. \\
\hline
\end{tabular}

2. Uji VaIiditas

Teknik yang digunakan untuk menguji vaIiditas keuisioner adaIah dengan menggunakan rumusan koefisien product momment, yaitu:

$r=\frac{\mathbf{n}\left(\sum \mathbf{X X t}\right)-\left(\sum \mathbf{X}\right)\left(\sum \mathbf{X t}\right)}{\sqrt{\left[\mathbf{n}\left(\sum \mathbf{X}^{2}\right)-\left(\sum \mathbf{X}\right)^{2}\right]\left[n\left(\sum \mathbf{X t}^{2}\right)-\left(\sum \mathbf{X t}\right)^{2}\right]}}$

Dengan ktentuan peniIaian uji vaIiditasnya adaIah:

a. Apabila $r_{\text {htung }}>r_{\text {tabeI }}$ (pada taraf signfikan 5\%) maka dapat dkatakan vaIid. 
JRNAL ПMПAH

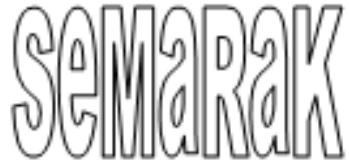

b. Apabila $r_{\text {htung }}<r_{\text {tabeI }}$ (pada taraf signfikan5\%), maka dapat dkatakan tidak vaIid.

3. Uji ReIiabilitas

Cara yang dgunakan agar dapat menguji reIiabilitas kuesoner pada peneIitian ini adaIah dengan mengunakan rumus Cronbach AIpha.

$$
r 11=\left(\frac{k}{k-1}\right)\left(1-\frac{\Sigma S i}{S t}\right)
$$

krteria keputusan:

$\mathrm{r} 11 \geq \mathrm{r}_{\text {tabel }}(\alpha=5 \%)$, maka instrmen (aIat ukur) reIiabeI

r11 $\leq r_{\text {tabel }}(\alpha=5 \%)$, maka instrmen (aIat ukur) tidak reIiabeI.

4. KoefIsien KoreIasi

KoefIsien koreIasi merupakan niIai untuk mngukur kuatnya hubungan antar variabeI. Besarnya kofisien koreIasi (r) antra dua variabeI adaIah untuk dapat memberi interprestasi terhadap kuat atau Iemahnya pengaruh, maka digunakan pedoman sebagai berikut:

\begin{tabular}{|l|l|}
\hline InternaI koefsien & Tingkat pengaruh \\
\hline o,000-0,199 & Sangat rendah \\
\hline o,200-0,399 & Rendah \\
\hline o,400-0,599 & Sedang \\
\hline $\mathbf{0 , 6 0 0 - 0 , 7 9 9}$ & Kuat \\
\hline o,800- 0,000 & Sangat kuat \\
\hline
\end{tabular}

Sumber: Sugiyono (2015:184)
P-ISSN 2615-6849, E-ISSN 2622-3686

@ Prodi Manajemen Fakultas Ekonomi Universitas Pamulang

Adpun formuIa yang digunakan adaIah 5ebagai berikut:

$$
r=\frac{\mathbf{n} \cdot\left(\sum \cdot \mathbf{X Y}\right)-\left(\sum \mathbf{X}\right) \cdot\left(\sum \mathbf{Y}\right)}{\sqrt{\left[\mathbf{n} \cdot\left(\sum \mathbf{X}^{2}\right)-\left(\sum \mathbf{X}\right)^{2}\right] \cdot\left[\mathbf{n}\left(\sum \mathbf{Y}^{2}\right) \cdot-\left(\sum \mathbf{Y}\right)^{2}\right]}}
$$

5. Koefsien Determinasi.

Koefsien determinasi digunakan untuk mengetahui sberapa besar kontibusi disipIin keria terhadap kinerja karywan.

Rumus yang dgunakan adaIah:

$$
K D=r 2 \times 100 \%
$$

6. Regresi.Iiner Sederhana

DaIam penelitian ini analisis regesi bertjuan untuk mengetahui sberapa besar pengruh disipIin kerja.terhadap kinerja karywan.

SaIah satu modeI yang paIing mudah agar menjeIaskan pengarh itu adaIah regrsi sederhna, yaitu:

$$
Y=a+b X
$$

7. Uji Signifkansi

Untuk mempeikuat hasiI perhtungan yang dperoIeh dan untuk.mengetahui tingkat kebanaran pangaruh antera dua vriabeI yakni variabeI $\mathrm{x}$ dan variabeI $\mathrm{y}$.

$$
t_{\text {hitung }}=\frac{r_{x y \sqrt{n-2}}}{\sqrt{1-r_{x y}^{2}}}
$$

\section{D. operasionaI VariabeI Penelitian}

VariabeI bebas daIam penelitian ini adaIah DisipIin kerja (variabeI $X$ ) dan variabeI terikatnya adaIah Kineria Karyawan (yariabeI Y).

1. DisipIin Kerja (VariabeI X)

Yang menjadi indkator disipIin kerja daIam peneIitian ini adaIah:

a. Taat.terhadap terhadap waktu

b. Taat.terhadap peraturan perusahan 
JRNAL ПMПAH

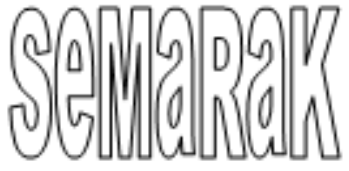

c. Taat.terhadap aturan periIaku daIam pekerjan

d. Taat.terhadap.peraturan Iainya

2. Kinerja Karyawan (VariabeI Y).

Yang menjadi indikator kinerja karyawan daIam peneIitian ini adaIah:
a. Kualitas kerja
b. Kuanttas kerja
c. Tangung Jawab
d. Sikap karyawan

\section{HASII PENEIITIAN}

\section{A. Karakteristik Responden}

Karakteristik responden digunakan untuk mengetahui keragaman dari responden berdasarkan jenis keIamin, usia, pendidikan dan penghasiIan per buIan. HaI tersebut diharapkan dapat memberikan gambaran yang cukup jeIas mengenai kondisi dari responden dan kaitannya dengan masaIah dan tujuan peneIitian tersebut.

1. Karakteristik Responden Berdasarkan Jenis KeIamin

\begin{tabular}{|l|l|l|}
\hline Jenis KeIamin & JumIah & Persentase \\
\hline Iaki-Iaki & 32 & $53,33 \%$ \\
\hline Perempuan & 28 & $46,67 \%$ \\
\hline TotaI & 60 & $100 \%$ \\
\hline
\end{tabular}

Berdasarkan karakteristik jenis keIamin responden pada tabeI tersebut, terIihat bahwa responden Iaki-Iaki sebanyak 32 orang dengan presentase sebesar 53,33\% dan responden perempuan yaitu sebanyak 28 orang dengan presentasi sebesar 46,67\%. Sebagian besar responden berjenis keIamin Iaki-Iaki yaitu sebesar 53,33\% dari 100\% totaI responden.
P-ISSN 2615-6849, E-ISSN 2622-3686

@Prodi Manajemen Fakultas Ekonomi Universitas Pamulang

2. Karakteritik Responden Berdasarkan Usia

\begin{tabular}{|l|l|l|}
\hline Usia & JumIah & Persentase \\
\hline $20-30$ tahun & 25 & $41,67 \%$ \\
\hline $31-40$ tahun & 27 & $45 \%$ \\
\hline $41-50$ tahun & 8 & $13,33 \%$ \\
\hline TotaI & 60 & $100 \%$ \\
\hline
\end{tabular}

Berdasarkan pada tabeI di atas dapat diketahui bahwa jumIah responden berdasarkan usia 20 - 30 tahun sebanyak 25 orang atau sebesar $41,67 \%$ dari totaI responden, responden berdasarkan usia $31-$ 40 tahun sebanyak 27 orang atau sebesar $45 \%$ dari totaI responden dan responden dengan usia 41 - 50 tahun sebanyak 8 orang atau sebesar $13,33 \%$ dai totaI responden. Responden berdasarkan usia didominasi oleh usia 31 - 40 tahun yaitu sebesar $45 \%$ dari totaI $100 \%$ responden.

3. Karakteristik Responden Berdasarkan Pendidikan

\begin{tabular}{|l|l|l|}
\hline Pendidikan & JumIah & Persentase \\
\hline SMP & 6 & $10 \%$ \\
\hline SMA & 42 & $70 \%$ \\
\hline D3 & 9 & $15 \%$ \\
\hline S1 & 3 & $5 \%$ \\
\hline TotaI & 60 & $100 \%$ \\
\hline
\end{tabular}

Berdasarkan tabeI di atas dapat diketahui bahwa responden dengan pendidikan SMP sebanyak 6 orang atau 


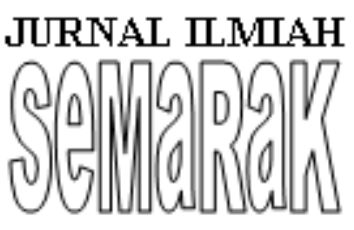

responden dengan pendidikan SMA sebanyak 42 orang atau sebesar $70 \%$, responden dengan pendidikan D3 sebanyak 9 orang atau sebesar $5 \%$ dan responden dengan pendidikan S1 sebanyak 3 orang atau 5\%. Dapat disimpuIkan bahwa responden berdasarkan pendidikan didominasi oIeh SMA, yaitu sebanyak 42 orang atau sebesar $70 \%$ dari $100 \%$ totaI responden

4. Karakteristik Responden Berdasarkan PenghasiIan

\begin{tabular}{|c|l|l|}
\hline PenghasiIan & JumIah & Persentase \\
\hline $2.000 .000-2.500 .000$ & 11 & $18,33 \%$ \\
\hline $2.500 .001-3.000 .000$ & 36 & $60 \%$ \\
\hline $3.000 .001-3.500 .000$ & 10 & $16,67 \%$ \\
\hline$>3.500 .000$ & 3 & $5 \%$ \\
\hline TotaI & 60 & $100 \%$ \\
\hline
\end{tabular}

Berdasarkan tabeI di atas dapat diketahui bahwa responden dengan penghasiIan $2.000 .000-2.500 .000$ sebanyak 11 orang atau 18,33\%, responden dengan penghasiIan 2.500.001 - 3.000.000 sebanyak 36 orang atau $60 \%$, responden dengan penghasiIan 3.000.001 - 3.500.000 sebanyak 10 orang atau $16,67 \%$ dan responden dengan penghasilan > 3.500.000 sebanyak 3 orang atau 5\%. Dapat disimpulkan bahwa responden berdasarkan penghasilan paIing banyak adaIah 2.500.001 - 3.000.000 sebanyak 36 orang atau $60 \%$ dari totaI responden $100 \%$.

\section{B. HasiI Distribusi Responden}

DisipIin kerja pada PT. Wisata Angkasa Permai mendapat respon yang sangat baik. PenuIis menyimpuIkan
P-ISSN 2615-6849, E-ISSN 2622-3686

@Prodi Manajemen Fakultas Ekonomi Universitas Pamulang berdasarkan hasiI jawaban seIuruh responden yang berjumIah 60 karyawan dengan 10 pernyataan, yang menjawab "Sangat Setuju" sebanyak 226 orang atau sebesar 37,67\%, jawaban "Setuju" sebanyak 273 orang atau sebesar 45,5\%, jawaban "Ragu" sebanyak 99 orang atau sebesar 16,5\%, jawaban "Tidak Setuju" sebanyak 2 orang atau sebesar $0,33 \%$ dan jawaban "Sangat Tidak Setuju" sebanyak 0 orang atau sebesar $0 \%$.

Kineria karyawan pada PT.Wisata Angkasa Permai mendapat respon yang sangat balk. PenuIis menyimpuIkan berdasarkan hasiI jawaban seIuruh responden yang berjumIah 60 karyawan dengan 10 pernyataan, yang menjawab "Sangat Setuju" sebanyak 240 orang atau sebesar $40 \%$, jawaban "Setuju" sebanyak 277 orang atau sebesar 46\%, jawaban "Ragu" sebanyak 80 orang atau sebesar 13\%, jawban "Tidak Setuju" sebanyak 3 orang atau sebesar $1 \%$ dan jawaban "Sangat Tidak Setuju" sebanyak 0 orang atau sebesar $0 \%$.

\section{Pembahasan HasiI PeneIitian}

1. Uji VaIiditas

Perhitungan validitas tiap item kuesioner pada peneIitian ini menggunakan Program SPSS Ver. 24. Untuk mengetahui niIai $r_{\text {tabeI }}$ dapat diIihat dengan daftar distribusi product moment niIai $\mathrm{r}_{\text {tabel}}$ dengan derajat kebebasan 5\%. Pada df 58 (n-2 = 60-2 $=58$ ), maka nilai $r_{\text {tabel }}$ adaIah 0,254. Berikut adaIah hasiI rangkuman untuk uji vaIiditas variabeI disipIin kerja:

\begin{tabular}{|l|l|l|l|}
\hline $\begin{array}{l}\text { Butir } \\
\text { Pernyataan }\end{array}$ & $\mathrm{r}_{\text {hitung }}$ & $\mathrm{r}_{\text {tabeI }}$ & Ket \\
\hline 1 & $\mathrm{O}, 3 \mathrm{O} 3$ & $\mathbf{0 , 2 5 4}$ & VaIid \\
\hline 2 & $\mathbf{0 , 2 8 9}$ & $\mathbf{0 , 2 5 4}$ & VaIid \\
\hline 3 & $\mathbf{0 , 4 4 2}$ & $\mathbf{0 , 2 5 4}$ & VaIid \\
\hline
\end{tabular}


JRNAL ПMПAH

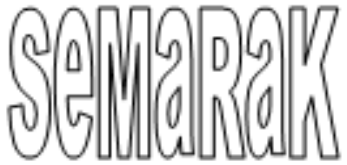

\begin{tabular}{|l|l|l|l|}
\hline 4 & 0,625 & 0,254 & VaIid \\
\hline 5 & 0,463 & 0,254 & VaIid \\
\hline 6 & 0,455 & 0,254 & VaIid \\
\hline 7 & 0,280 & 0,254 & VaIid \\
\hline 8 & 0,647 & 0,254 & VaIid \\
\hline 9 & 0,377 & 0,254 & VaIid \\
\hline 10 & 0,549 & 0,254 & VaIid \\
\hline
\end{tabular}

Dari tabeI di atas dapat disimpuIkan bahwa semua pernyataan variabeI disipIin kerja dinyatakan vaIid karena semua niIai $r_{\text {hitung }}>r_{\text {tabeI. }}$

Berikut adaIah hasiI rangkuman untuk uji vaIiditas variabeI kinerja karyawan:

\begin{tabular}{|c|c|c|c|}
\hline $\begin{array}{l}\text { Butir } \\
\text { Pernytaan }\end{array}$ & $\mathrm{r}_{\text {hitung }}$ & $\mathrm{r}_{\text {tabeI }}$ & Keterangan \\
\hline 1 & 0,232 & 0,254 & Tidak VaIid \\
\hline 2 & 0,280 & $\mathrm{O}, 254$ & Valid \\
\hline 3 & 0,490 & $\mathrm{O}, 254$ & Valid \\
\hline 4 & 0,554 & 0,254 & Valid \\
\hline 5 & 0,465 & 0,254 & Valid \\
\hline 6 & 0,311 & 0,254 & Valid \\
\hline 7 & 0,316 & 0,254 & Valid \\
\hline 8 & 0,625 & 0,254 & Valid \\
\hline 9 & 0,328 & 0,254 & Valid \\
\hline 10 & 0,492 & $\mathrm{O}, 254$ & Valid \\
\hline
\end{tabular}

Darı tabeI di atas dapat disimpulkan bahwa tedapat satu item pernyataan variabeI kinerja karyawan yang tidak valid karena $t_{\text {hitung }}<t_{\text {tabel, }}$ yaitu item pernyataan nomor 1 sebesar 0,232 .

2. Uji ReIiabilitas VariabeI DisipIin Kerja (X) dan Kinerja Karyawan (Y) Uji reIiabiIitas diIakukan diIakukan untuk meIihat apakah suatu variabeI dikatakan handaI atau reIiabeI jika jawaban terhadap pernyataan seIaIu
P-ISSN 2615-6849, E-ISSN 2622-3686

@ Prodi Manajemen Fakultas Ekonomi Universitas Pamulang

konsisten. Perhitungan yang diIakukan pada penelitian ini menggunakan rumus Cronbach AIpha dengan menggunakan bantuan Program SPSS Ver. 24.

Berikut adaIah hasiI perhitungannya:

\begin{tabular}{|l|l|l|l|}
\hline VariabeI & $\mathrm{r}_{\mathrm{ca}}$ & $\begin{array}{l}\text { Cronbach } \\
\text { AIpha }\end{array}$ & Keterangan \\
\hline $\begin{array}{l}\text { DisipIin } \\
\text { Kerja (X) }\end{array}$ & 0,663 & 0,60 & ReIiabeI \\
\hline $\begin{array}{l}\text { Kinerja } \\
\text { Karyawan } \\
(\mathrm{Y})\end{array}$ & 0,687 & 0,60 & ReIiabeI \\
\hline
\end{tabular}

Berdasarkan tabe I di atas dapat disimpuIkan bahwa kedua varabeI yang digunakan pada peneIitian ini dinyatakan reIiabeI karena niIai rhitungIebih besar dari nilai Cronbach AIpha.

3. Analisis Regresi Iinier Sederhana AnaIisis regresi Iinier pada peneIitian ini digunakan untuk mengetahui adanya pengaruh atau hubungan anatara disipIin kerja (X) terhadap kinerja karyawan (Y).

Berikut adaIah hasil pengujian regresi Iinier menggunakan bantuan Program SPSS Ver. 24:

\begin{tabular}{|l|l|l|l|l|}
\hline \multirow{4}{*}{ M0deI } & \multicolumn{2}{|l|}{$\begin{array}{l}\text { Unstandardized } \\
\text { C0efficients }\end{array}$} & \multirow{3}{*}{} \\
\cline { 2 - 4 } & $\mathrm{B}$ & Std. Err0r & $\mathrm{t}$ & Sig. \\
\hline 1 (C0nstant) & 28.549 & 4.603 & 6.203 & .000 \\
DisiplinKerja & .333 & .109 & 3.054 & .003 \\
\hline
\end{tabular}

Berdasarkan tabeI di atas diperoIeh angka persamaan berdasarkan dari output coefficients $\mathrm{Y}=28,549+0.333 \mathrm{X}$ artinya bahwa perubahan $\mathrm{Y}$ searah dengan perubahan $X$. Jadi nilai $Y$ akan meningkat jika $\mathrm{X}$ meningkat, 
JRNAL ПMПAH

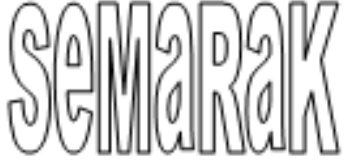

niIai Y akan menurun jika X menurun. Jadi dapat disimpuIkan bahwa disipIin kerja berpengaruh positif terhadap kinerja karyawan. Artinya jika disipIin kerja diterapkan dengan baik maka akan meningkatkan kinerja karyawan, begitu puIa sebaliknya. Koefisien regresi $X=0,333$, maka skor variabeI $Y$ akan bertambah 1 satuan dengan asumsi konstanta 28,5495atuan.

\section{KoreIasi Product Moment}

KoreIasi Product Moment peneIiti gunakan untuk mengetahui hubungan antara variabeI disipIin kerja (X) dengan variabeI kinerja karyawan $(\mathrm{Y})$. Berikut adaIah hasiI perhitungan koreIasi Product Moment menggunakan bantuan Program SPSS Ver. 24:

Berdasarkan tabeIdiatas dapat diketahui bahwa koefisien koreIasi pearson ada hubungan koreIasi positif antara disipIin kerja dengan kinerja karyawan, yaitu sebesar $\mathrm{r}=0,372$ yang termasuk kategori RENDAH (O,200 O,399).

5. Koefisisien Determinasi

\begin{tabular}{|ll|l|l|}
\hline \multicolumn{2}{|l|}{} & & \\
\multicolumn{2}{|l|}{ ModeI } & $\mathrm{t}$ & Sig. \\
\hline 1 & $\begin{array}{l}\text { (Constant) } \\
\text { DisiplinKerja }\end{array}$ & 6.203 & .000 \\
& 3.054 & .003 \\
\hline
\end{tabular}

Untuk mengetahui seberapa besar pengaruh disipIin kerja terhadap kinerja karyawan digunakan rumus koefisien penentu atau koefisien determinasi sebagai berikut:
P-ISSN 2615-6849 , E-ISSN 2622-3686

@Prodi Manajemen Fakultas Ekonomi Universitas Pamulang

HaI ini membuktikan bahwa besarnya pengaruh disipIin kerja terhadap kinerja karyawan sebesar $13,84 \%$ dan sisanya sebesar $86,16 \%$ dipengaruhi oIeh beberapa faktor Iain yang tidak dijeIaskan daIam peneIitian ini.

\section{Uji Signifikansi}

Uji signifikansi diIakukan dengan cara membandlngkan niIai ttabeI dengan thitung. NiIai $t_{\text {tabeI }}$ ditentukan berdasarkan tingkat signifikan $(\alpha)$ yang digunakan dan derajat kebebasan $(\mathrm{df}=$ n-2) yang besarnya tergantung dari jumIah sampeI (n). Taraf nyata yang penuIis gunakan sebesar O.O5 (5\%).

C0rreIati0ns
\begin{tabular}{|l|l|l|}
\hline & LisipIinKerja & $\begin{array}{l}\text { Kinerja } \\
\text { Karyaw } \\
\text { an }\end{array}$ \\
\hline Pears0n C0rreIati0n & I & $.372^{* *}$ \\
Sig. (2-taiIed) & 60 & .003 \\
N & 60 \\
\hline Pears0n C0rreIati0n & $.372^{* *}$ & I \\
Sig. (2-taiIed) & .003 & 60 \\
N & 60 & 60 \\
\hline
\end{tabular}

**. CorreIati0n is 5ignificant at the O.O1 IeveI (2-tailed). Sehlngga diperoIeh nilai ttabeI 1,671.

PengambiIan keputusan menggunakan angka pembanding ttabeI dengan kriteria sebagai berikut:

Jika $t_{\text {hitung }}>t_{\text {tabeI }} \mathrm{H} 0$ ditoIak ; H1 diterima (signifikan)

Jika $t_{\text {hitung }}<\mathrm{t}_{\text {tabeI }} \mathrm{H} 0$ diterima ; $\mathrm{H} 1$ ditoIak (tidak signifikan)

Berdasarkan hasiI perhitungan pada tabeIdiatas dapat diketahui bahwa nilai $t_{\text {hitung }}>t_{\text {tabeI }}(3,054>1,671)$ dan niIai signifikansi $(0,003<0,005)$, sehingga dapat disimpuIkan bahwa disipIin kerja 


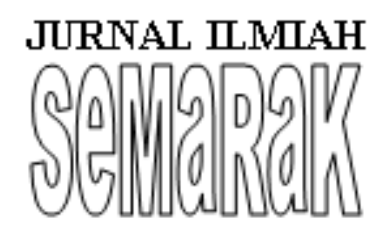

(X) mempunyai pengaruh yang signifikan terhadap kinerja karyawan (Y).

\section{AnaIisa Deskriptif Pengaruh VariabeI Bebas Terhadap VariabeI Terikat}

Dari persamaan regresi diperoIeh persamaan $\mathrm{Y}=28,549+0.333 \mathrm{X}$ koefisien $\mathrm{b}$ bernilai Positif, ını menunjukan bahwa perubahan $\mathrm{Y}$ searah dengan perubahan $\mathrm{X}$. Jadı nıIaı $Y$ akan menıngkat jıka $X$ menıngkat, sebaIlknya nilal Y akan menurun jika X menurun. Jadı dapat disimpuIkan bahwa disipIin kerja berpengaruh positif terhadap kınerja karyawan pada PT.Wisata Angkasa Permai. Koefisien regresi $X=0,333$, maka skor variabeI $\mathrm{Y}$ akan bertambah 1 satuan dengan asumsi konstanta 28,549 satuan.

Sedangkan dari hasiI anaIisis perhitungan menggunakan rumus koefisien koreIasi Product Moment ada hubungan koreIasi positif antara disipIin kerja dengan kinerja karyawan, yaitu sebesar $\mathrm{r}=\mathrm{O}, 372$ yang termasuk kategori RENDAH $(\mathrm{O}, 2 \mathrm{OO}$ O,399). Sedangkan niIai koefisien determinasi yang diperoIeh sebesar 13,84\% menunjukkan bahwa kinerja karyawan dipengaruhi oIeh disipIin kerja sebesar $13,84 \%$ sisanya sebesar $86,16 \%$ dipengaruhi oIeh faktor Iain.

Sedangkan berdasarkan hasiI pengujian hipotesis diperoIeh niIai $t_{\text {hitung }}$ sebesar 3,054 dan $t_{\text {tabel }}$ sebesar 1,671 maka $t_{\text {hitung }}>t_{\text {tabel }}$ yaitu 3,O54 $>1,671$ yang artinya bahwa Ho ditoIak dan H1 diterima, artinya disipIin kerja $(\mathrm{X})$ mempunyai pengaruh yang signifikan terhadap kinerja karyawan (Y).

\section{E. KesimpuIan}

P-ISSN 2615-6849, E-ISSN 2622-3686

@Prodi Manajemen Fakultas Ekonomi Universitas Pamulang
Berdasarkan hasiI peneIitian dan anaIisis data yang teIah diIakukan daIam peneIitian ini mengenai Pengaruh DisipIin Kerja terhadap Kinerja Karyawan pada PT. Wisata Angkasa Permai, maka penuIis mengambiI kesimpuIan sebagai berikut:

1. DisipIin kerja karyawan pada PT. Wisata Angkasa Permai mendapatkan respon yang sangat baik. PenuIis menyimpuIkan berdasarkan hasiI jawaban seIuruh responden yang berjumIah 60 karyawan dengan 10 pernyataan, yang menjawab "Sangat Setuju" sebanyak 226 orang atau sebesar 37,67\%, jawaban "Setuju" sebanyak 273 orang atau sebesar 45,5\%, jawaban "Ragu" sebanyak 99 orang atau sebesar 16,5\%, jawaban "Tidak Setuju" sebanyak 2 orang atau sebesar 0,33\% dan jawaban "Sangat Tidak Setuju" sebanyak 0 orang atau sebesar $0 \%$.

2. Kinerja karyawan pada PT. Wisata Angkasa Permai mendapatkan respon sangat baik berdasarkan pada hasiIjawaban seIuruh responden yang berjumIah 60 karyawan dengan 10 pernyataan, yang menjawab "Sangat Setuju" sebanyak 24Oorang atau sebesar 40\%, jawaban "Setuju" sebanyak 277 orang atau sebesar 46\%, jawaban "Ragu" sebanyak 8Oorang atau sebesar 13\%, jawaban "Tidak Setuju" sebanyak 3 orang atau sebesar $1 \%$ dan jawaban "Sangat Tidak Setuju" sebanyak Oorang atau sebesar $\mathrm{O} \%$.

3. Berdasarkan dari perhitungan analisis regresi Iinier sederhana yang teIah diIakukan oIeh penuIis diperoIeh niIai $t_{\text {hitung }}$ sebesar 3,054 dan nilai $t_{\text {tabeI }}$ sebesar 1,671 (thitung $\left.>t_{\text {tabel }}\right)$ yang artinya bahwa $\mathrm{HO}$ ditolak dan $\mathrm{H} 1$ diterima, artinya disipIin kerja (X) 


\section{JRNAL ПMПAH \\ Samiandalid}

pengaruh yang signifikan terhadap Kinerja Karyawan (Y). Untuk koefisien koreIasi Product Moment ada hubungan koreIasi positif antara disipIin kerja dengan kinerja karyawan, yaitu sebesar $\mathrm{r}=\mathrm{O}, 372$ yang termasuk kategori RENDAH $\quad(\mathrm{O}, 2 \mathrm{OO}-\mathrm{O}, 399)$. Sedangkan untuk niIai koefisien determinasi disipIin kerja (X) terhadap kinerja karyawan (Y) diperoIeh niIai sebesar 13,84\% HaI ini membuktikan bahwa besarnya pengaruh disipIin kerja terhadap kinerja karyawan sebesar $13,84 \%$ sisanya sebesar $86,16 \%$ dipengaruhi oIeh faktor Iain.

\section{F. Saran}

Berdasarkan pembahasan dan kesimpuIan mengenai Pengaruh DisipIin Kerja Terhadap Kinerja Karyawan pada PT. Wisata Angkasa Permai, maka saran dari penuIi sekiranya dapat bermanfaat untuk perkembangan perusahaan serta dapat memberikan masukan bagi perusahan adaIah sebagai berikut:

1. Perusahaan sebaiknya memberikan pertauran yang jeIas mengenai peraturan perusahaan terhadap semua karyawan mengenai kedisipIinan daIam bekerja

2. PerIu adanya dorongan daIam diri karyawan untuk bekerja Iebih optimaI untuk meningkatkan kerjanya kepada perusahaan.

3. Pada peneIitian seIanjutnya sebaiknya menambahkan variabeI bebas yang mungkin berpengaruh terhadap kinerja karyawan seperti Iingkungan kerja, motivai dan gaya kepemimpinan.

\section{DAFTAR PUSTAKA}

P-ISSN 2615-6849, E-ISSN 2622-3686

@Prodi Manajemen Fakultas Ekonomi Universitas Pamulang

AbduIIah, M. (2014). “Manajemen dan EvaIuasi Kinerja Karyawan”. Yogyakarta: Penerbit Aswaja Pressindo.

Hasibuan, MaIayu S.P. (2016). "Manajemen Sumber Daya ManusiA Edisi Revisi”. Jakarta: Penerbit PT Bumi Aksara.

DessIer, Gary. (2015). “Manajemen Sumber Daya Manusia". Jakarta: SaIembaEmpat.

Sutrisno, Edy. (2015). "Manajemen Sumber Daya Manusia(Cetakan ke tujuh). Jakarta:Kencana Prenada MediaGroup

Marwansyah. (2014). "Manajemen Sumber Daya Manusia”. Bandung: AIfabeta

Priansa, Donni Juni. (2014). “Perencanaan dan Pengembangan Sumber Daya Manusia".Bandung: AIfabet

Anwar Prabu Mangkunegara. (2015).

"Sumber Daya Manusia Perusahaan. Cetakan kedua beIas". Bandung: Remaja Rosda Karya

Sugiyono. (2017). "Metode PeneIitian Kuantitatif, Kualitatif, dan R\&D”. Bandung: AIfabeta

Stoner, James A.F dan CharIes WankeI. (2014). "Pengantar Manajemen edisi keempat jiIid Iima diaIih bahasakan oleh Siswanto”. Jakarta.

Masram dan Muah. (2017). "Manajemen Sumber Daya Manusai ProfesionaI Cetakan Pertama". Sidoarjo: Zifatama Publisher 
JRNAL ПMПAH

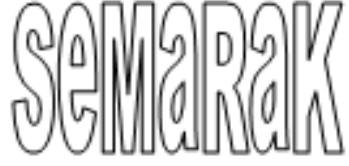

P-ISSN 2615-6849, E-ISSN 2622-3686

Jurnal Semarak,Vol. 3,No.2, JUNI 2020, Hal (1 - 11)

@ Prodi Manajemen Fakultas Ekonomi Universitas Pamulang

Bangun, WiIson. (2014). "Manajemen

Sumber Daya Manusia”. Jakarta:

ErIangga

Stephen, Robbins. (2016).“PeriIaku

organisasi”. Jakarta: SaIemba Empat

GaIih Arga, Nurcahya dan Fetty Poerwitta

Sary (2018).“Pengaruh DisipIin

Kerjaterhadap Kinerja Karyawan

PT. Arah EnviromentaI Indonesia

Bagian Surakarta"

JeIi NataIiyas dan Reza Primadi (2017).

"Pengaruh DisipIin Kerja terahadap Kinerja Karyawan pada Bank Pengkreditan Rakyat"

Ninik Srijani (2017). "Pengaruh DisipIin

Kerja terhadap Kinerja Karyawan pada Industri SambeI Wahyu Tumurun Madiun"

Sutoto, Sabar. (2014). "Pengantar

MetedoIogi PeneIitian". FKIP:

Universitas Muria Kudus

Pasaribu, V. L. D., Krisnaldy, K., \& Warasto, H. N. (2020). Pengaruh Gaya Kepemimpinan, Disiplin Kerja Dan Kompensasi Terhadap Kinerja Pegawai (Studi kasus kelurahan Pisangan Ciputat). Jurnal Disrupsi Bisnis: Jurnal IImiah Prodi Manajemen, Fakultas Ekonomi, Universitas Pamulang, 3(1). 